\title{
Atmospheric Deposition of Inorganic Elements and Organic Compounds at the Inlets of the Venice Lagoon
}

\author{
E. Morabito, ${ }^{1}$ D. Contini, ${ }^{2}$ F. Belosi, ${ }^{3}$ A. M. Stortini, ${ }^{4}$ L. Manodori, ${ }^{5}$ and A. Gambaro ${ }^{1,6}$ \\ ${ }^{1}$ Institute for the Dynamics of Environmental Processes (IDPA), CNR, 30123 Venice, Italy \\ ${ }^{2}$ Istituto di Scienze dell'Atmosfera e del Clima (ISAC), CNR, 73100 Lecce, Italy \\ ${ }^{3}$ Istituto di Scienze dell'Atmosfera e del Clima (ISAC), CNR, 40129 Bologna, Italy \\ ${ }^{4}$ Department of Molecular Science and Ecosystem (DSMN), Ca' Foscari University, 30123 Venice, Italy \\ ${ }^{5}$ Veneto Nanotech, 45100 Rovigo, Italy \\ ${ }^{6}$ Department of Environmental Sciences, Informatics and Statistics (DAIS), Ca' Foscari University, 30123 Venice, Italy
}

Correspondence should be addressed to E. Morabito; elisa.morabito@unive.it

Received 7 March 2014; Revised 18 June 2014; Accepted 18 June 2014; Published 7 July 2014

Academic Editor: Gianluigi De Gennaro

Copyright (c) 2014 E. Morabito et al. This is an open access article distributed under the Creative Commons Attribution License, which permits unrestricted use, distribution, and reproduction in any medium, provided the original work is properly cited.

\begin{abstract}
The Venice Lagoon is subjected to long-range transport of contaminants via aerosol from the near Po Valley. Moreover, it is an area with significant local anthropogenic emissions due to the industrial area of Porto Marghera, the urban centres, and the glass factories and with emissions by ships traffic within the Lagoon. Furthermore, since 2005, the Lagoon has also been affected by the construction of the MOSE (Modulo Sperimentale Elettromeccanico-Electromechanical Experimental Module) mobile dams, as a barrier against the high tide. This work presents and discusses the results from chemical analyses of bulk depositions, carried out in different sites of the Venice Lagoon. Fluxes of pollutants were also statistically analysed on PCA with the aim of investigating the spatial variability of depositions and their correlation with precipitations. Fluxes of inorganic pollutants depend differently on precipitations, while organic compounds show a more seasonal trend. The statistical analysis showed that the site in the northern Lagoon has lower and almost homogeneous fluxes of pollutants, while the other sites registered more variable concentrations. The study also provided important information about the annual trend of pollutants and their evolution over a period of about five years, from 2005 to 2010 .
\end{abstract}

\section{Introduction}

Average annual mass fluxes of atmospherically deposited dust are estimated at 8,12 , and $35 \mathrm{~g} \cdot \mathrm{m}^{-2}$ in the Western Mediterranean (WMED), Central Mediterranean (CMED), and Eastern Mediterranean (EMED), respectively [1]. Atmospheric dust deposition is the most important part of the geochemical cycles of several elements and organic compounds, and its chemical composition could provide valuable information about sources of air pollution in specific areas $[2,3]$. Depending on their origin, major, and trace, inorganic elements in the atmosphere can be distinguished into natural (e.g., $\mathrm{Na}, \mathrm{Mg}, \mathrm{K}, \mathrm{Ca}, \mathrm{Si}$, and $\mathrm{Al}$ ) and anthropogenic (e.g., $\mathrm{V}, \mathrm{Cr}, \mathrm{Mn}, \mathrm{Ni}, \mathrm{Cu}, \mathrm{Zn}, \mathrm{Cd}$, and $\mathrm{Pb}$ ) emissions. Elements such as $\mathrm{As}, \mathrm{Se}, \mathrm{Cd}, \mathrm{Pb}, \mathrm{Sb}, \mathrm{Se}, \mathrm{Cr}, \mathrm{Co}, \mathrm{Cu}, \mathrm{Ga}$, and $\mathrm{Mo}$ are emitted by coal combustion, while $\mathrm{V}, \mathrm{Ni}$, and $\mathrm{Pb}$ are emitted mostly by oil combustion; $\mathrm{V}$ and $\mathrm{Ni}$ may also be tracers of ship traffic emissions; $\mathrm{Cu}, \mathrm{Zn}, \mathrm{Pb}$, and $\mathrm{Sb}$ are often associated with traffic emissions and road dust [4]. Trace metals atmospherically transported are transmitted to marine biogeochemical cycles following the deposition of aerosols at the sea surface by either "wet" or "dry" deposition. Polycyclic aromatic hydrocarbons (PAHs) are "semivolatile" organic compounds (SOC) and are persistent and ubiquitous in the environment, and the atmosphere is their major transport and deposition pathway. As PAHs are produced primarily during incomplete combustion of fossil fuels and wood, their major sources are residential heating, open burning, coke and aluminium production, and vehicle exhausts. These compounds persist in the environment and are liable to bioaccumulation through the food web. They therefore pose a risk to human health and the environment [5]. The city 
of Venice, the object of the present study, is located in an area at the edge of the Po Valley and is subjected to long-range transport of elements and organic compounds via aerosol from the valley [6]. It is also characterised by significant local anthropogenic emissions from the industrial area of Porto Marghera, urban areas, glass factories, and ship traffic within the Lagoon. Furthermore, since the beginning of 2005, the Venice Lagoon has also been affected by emissions linked to the construction of the MOSE (Modulo Sperimentale Elettromeccanico-Electromechanical Experimental Module) mobile dams, one for each inlet connecting the Lagoon to the Adriatic Sea (Chioggia, Malamocco, and Lido). Previous studies of bulk depositions in the Venice Lagoon primarily focused on the role of the industrial area of Porto Marghera [7-9]. Guerzoni et al. [10] analysed daily fluxes of polychlorobiphenyls (PCBs), hexachlorobenzene (HCB), polychlorinated dibenzop-dioxins, and dibenzofurans $(\mathrm{PCDD} / \mathrm{Fs})$ in bulk depositions distributed in different sites of the Venice Lagoon, with the aim of investigating the spatial distribution of organic compounds and the impact of the industrial site.

The aim of the present work is to investigate the spatial variability of depositions in the Venice Lagoon, its correlation with precipitations, and the possible impact of the construction of the MOSE dams, by studying the fluxes of inorganic and organic pollutants in the areas next to the construction sites. Our study also provides precious temporal information about the presence of contaminants in the atmosphere of the Lagoon.

\section{Data and Methodology}

2.1. Sampling. Samples of bulk depositions cover a temporal range of about 5 years, from July 2005 to March 2010. The sampling was not a continuous activity; nevertheless, more than one hundred sample campaigns were carried out during this period in six sites located in different areas of the Venice Lagoon. Sampling sites were connected to the three Lagoon inlets and next to the MOSE construction yards. Each campaign lasted 32 days on average, at the end of which the related sample of bulk deposition was collected.

The positions of the samplers are shown in Figure 1: deposimeters D1-D4 were placed at the Lido inlet, D5 was placed at the Malamocco inlet, and D6 was placed at the Chioggia inlet (Figure 1).

In order to study the contribution of construction activities to the atmospheric pollution of the area, by determining the principal organic and inorganic pollutants in depositions, four samplers were placed next to the Lido inlet, at different distances from the construction site: the deposimeter D1, which was located within the construction area, recorded direct emissions from its activities; D2 was located several hundred metres from D1, on the seafront; D3 was placed at the same distance from D1 but four metres above the ground to avoid the influence of local events; D4 was located at a distance of $2 \mathrm{~km}$ from the construction site, in an area not affected by local traffic (Figure 1, details). These samplers simultaneously collected bulk depositions from January 2005

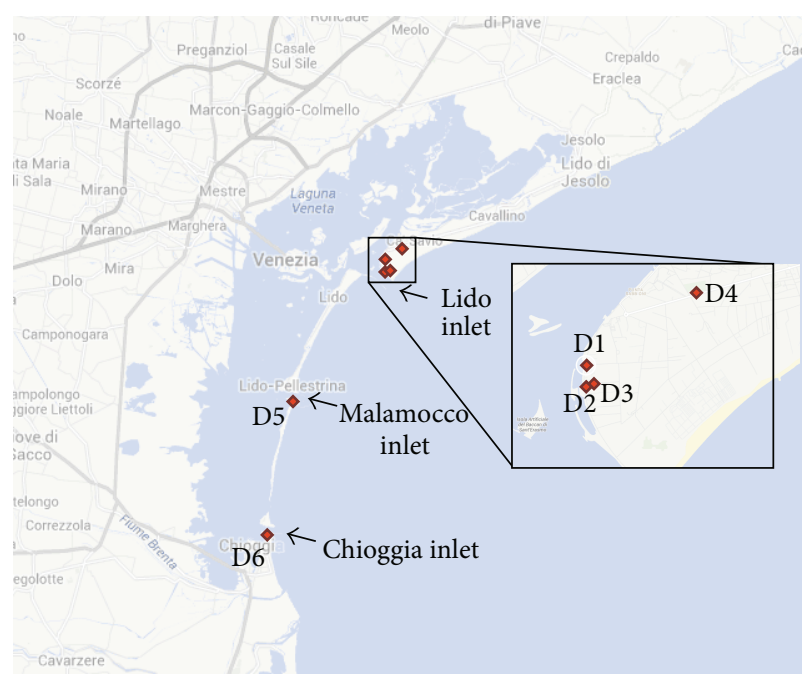

Figure 1: Maps of the sites of the deposimeters.

to May 2006. In order to evaluate spatial differences of the fluxes of contaminants in the Lagoon, depositions in Malamocco (central Lagoon) and Chioggia inlets (southern Lagoon) were also collected.

Precipitation data, when available, were registered from a meteorological station located near the sampling site D4 provided by the ARPAV (Veneto Regional Agency for Environmental Prevention and Protection). The precipitation data collected by the recording rain gauge Ceppe located near the sampling site D5, provided by MAV (Ministero delle Infrastrutture e dei Trasporti Magistrato alle Acque di Venezia-Italian Ministry of Infrastructure and Transport), were also considered.

The precipitation daily data were integrated during the period of the depositions' exposure, with the aim of investigating the relation of precipitation with the fluxes of contaminants.

Bulk depositions were collected into 1-meter-high passive stainless steel samplers, composed of two cylindrical supports and two vessels-one made of polyethylene and the other of glass-suitable for the simultaneous determination of inorganic and organic pollutants. The polyethylene vessel, which was used for the determination of inorganic pollutants, was repeatedly washed with Milli-Q water at $2 \%$ $\mathrm{HNO}_{3}$ Suprapur; the glass vessel, which was used for the determination of organic pollutants, was repeatedly washed with organic solvents. At the end of each sampling time, the depositions were measured with a graduate glass and stored into vessels made of LDPE (low density polyethylene) (for the analysis of inorganic contaminants) or glass (for the determination of organic contaminants). The remaining particulate matter adhering to the surface of the sampler's vessels was collected by filters made of mixed cellulose esters (for the determination of inorganic contaminants) or quartz fibre (for the determination of organic contaminants). Moreover, at the end of each sampling time, a blank was also collected by washing the sampler's vessel with Milli-Q water and by cleaning the vessels' surface with filters. 


\subsection{Analytical Methods}

2.2.1. Organic Pollutants. Analyses of organic pollutants were carried out in the CSMO (Centro Studi Microinquinanti Organici-Study Centre of Organic Micropollutants) laboratory in Voltabarozzo, Padua, Italy. The water samples used for the analysis of organic pollutants were treated by continuous liquid-liquid extraction to obtain organic samples using a mixture of hexane-dichloromethane $(1: 1)$; the particulate matter collected with filters was extracted by a sonic bath, using a mixture of pentane-dichloromethane $(2: 1)$ in a closed flask. The two mixed extracts were dehydrated with anhydrous sodium sulphate, and the volume was reduced to $5 \mathrm{~mL}$ under a nitrogen flow at $23^{\circ} \mathrm{C}$ (Turbovap II Zimark) and cleaned using an automated multicolumn system (Power-Prep, Fluid Management System Inc.). The resulting samples were loaded onto a packed neutral silica column (flow: $2 \mathrm{~mL} \mathrm{~min}^{-1}$ ) previously conditioned with $50 \mathrm{~mL}$ of n-hexane (flow: $10 \mathrm{~mL} \mathrm{~min}^{-1}$ ) and then eluted with $30 \mathrm{~mL}$ of $\mathrm{n}$-hexane (flow: $10 \mathrm{~mL} \mathrm{~min}^{-1}$ ) followed by $30 \mathrm{~mL}$ of $\mathrm{n}$-hexane/dichloromethane $\left(1: 1\right.$; flow: $\left.5 \mathrm{~mL} \mathrm{~min}^{-1}\right)$. The final volume was reduced to $500 \mu \mathrm{L}, 100 \mu \mathrm{L}$ of isooctane was added, and the volume was reduced again to $100 \mu \mathrm{L}$. The solutions obtained were analysed with a MAT 95XP (Thermo Finnigan) high-resolution mass spectrometer, equipped with a Hewlett-Packard model 5890 series II gas chromatograph.

Before extraction, carbon-13-labelled IPA (phenanthrene) was added to the extracts as internal standard. The samples were checked for external contamination by analysing the blanks. The samplers were cleaned twice using filters and $125 \mathrm{~mL}$ of dichloromethane: the analysis of the dichloromethane and the filters constituted the blank. LOD was calculated from the average value of the blanks, plus three standard deviations, while the precision was evaluated by four analyses of a water sample spiked with a known quantity of PAHs.

Gas chromatographic separation was performed with a fused silica capillary column (J\&W Scientific DB-5MS, $60 \mathrm{~m} \times 0.25 \mathrm{~mm}$ O.D. $0.25 \mu \mathrm{m}$ film thickness). Detailed operating conditions were described in a previous paper [11]. PAHs analysed in this study are as follows: naphthalene, acenaphthylene, acenaphthene, fluorene, phenanthrene, anthracene, fluoranthene, pyrene, benz(a)anthracene, chrysene, benzo(b)fluoranthene, benzo(k)fluoranthene, benzo(a)pyrene, indenopyrene, dibenz(a,h)anthracene, and benzo(g,h)perylene.

2.2.2. Inorganic Pollutants. Each filter was digested by microwave (Ethos1-Milestone) inside a Teflon vessel (100 mL) held in a 10-place high-pressure carousel (Milestone HPR1000/10S High Pressure) with $5 \mathrm{~mL} \mathrm{HNO}_{3}$ and $1 \mathrm{~mL} \mathrm{HF}$ (Romil UPA). The digestion temperature programme consisted of a ramp from room temperature to $100^{\circ} \mathrm{C}$ in $10 \mathrm{~min}$, followed by a time sequence $(5 \mathrm{~min} / \mathrm{step})$, allowing the maintenance and increase $\left(\Delta t 20^{\circ} \mathrm{C}\right)$ of the temperature to $180^{\circ} \mathrm{C}$, after which this value was maintained for $10 \mathrm{~min}$. In all the digestion sessions, one vessel was used as blank to check the quality of the reagent and the procedure. The digested samples and the blanks were both diluted to $30 \mathrm{~mL}$ with ultrapure water. Between two sample digestions, the vessels were cleaned using a microwave programme $(20 \mathrm{~min} /$ slope from room temperature to $160^{\circ} \mathrm{C}$ and $10 \mathrm{~min}$ at $160^{\circ} \mathrm{C}$ ) with $10 \mathrm{~mL}$ of $\mathrm{HNO}_{3}$ (Romil Suprapur) and $1 \mathrm{~mL} \mathrm{HF}$ (Romil UPA).

Water samples were also digested by microwave (8 $\mathrm{min} / \mathrm{slope}$ from room temperature to $160^{\circ} \mathrm{C}$ and $10 \mathrm{~min}$ at $160^{\circ} \mathrm{C}$ ). Each vessel contained $2 \mathrm{~mL} \mathrm{HNO}_{3}$ and $18 \mathrm{~mL}$ of the deposition sample. All manipulations were conducted in a clean room equipped with a laminar flow bench.

The accuracy and precision of the method were controlled using the standard reference material (Urban Particulate Matter NIST1684). LOD was calculated for each element from the average value of the blanks, plus three standards; the detailed calculation of the relative error was reported in a previous paper [12].

Inorganic elements in the depositions samples were measured by Inductively Coupled Plasma-Quadrupole Mass Spectrometry (ICP-QMS Agilent 7500I). The inorganic elements analysed in this study are as follows: $\mathrm{As}, \mathrm{Cd}, \mathrm{Co}, \mathrm{Cr}$, $\mathrm{Cu}, \mathrm{Fe}, \mathrm{Mo}, \mathrm{Ni}, \mathrm{Pb}, \mathrm{Sb}, \mathrm{Tl}, \mathrm{V}$, and $\mathrm{Zn}$. Determination of iron, copper, and zinc was carried out only on samples collected after 2007.

2.2.3. Statistical Analysis of Data. The data obtained were statistically analysed using the PCA (Principal Component Analysis) contained in the package STATISTICA 6.0 (StatSoft, Inc., 2001, Tulsa, OK, USA). We applied an autoscaling procedure on all the continuous variables, namely, the precipitation measured in $\mathrm{mm}$ of water, and the fluxes of the majority of elements and organic compounds. The analytes whose samples were often under detection limit were excluded from our statistical analysis.

\section{Results and Discussions}

Our first analysis regarded the contribution of the MOSE construction activities to the atmospheric depositions at the Lido inlet. This contribution was studied through a chemical analysis of depositions simultaneously collected in four different deposimeters (D1, D2, D3, and D4), placed at different distances from the construction site, from January 2005 to May 2006.

Figures 2 and 3 report the total average concentrations of inorganic and organic pollutants in depositions collected from January 2005 to May 2006 in the deposimeters D1, D2, D3, and D4. The fluxes of organic compounds were often under the detection limit, which is why they were omitted from Figure 3. The total average concentration for the whole sampling period was higher in D1 than in other samplers for all the pollutants analysed, both inorganic and organic. For some elements, such as vanadium, chromium, nickel, and lead, the difference between D1 and the other deposimeters was significantly greater. Average concentrations in the deposimeters D2, D3, and D4 were comparable, with no evidence of any inverse correlation between element concentration and the distance from the construction site. The 


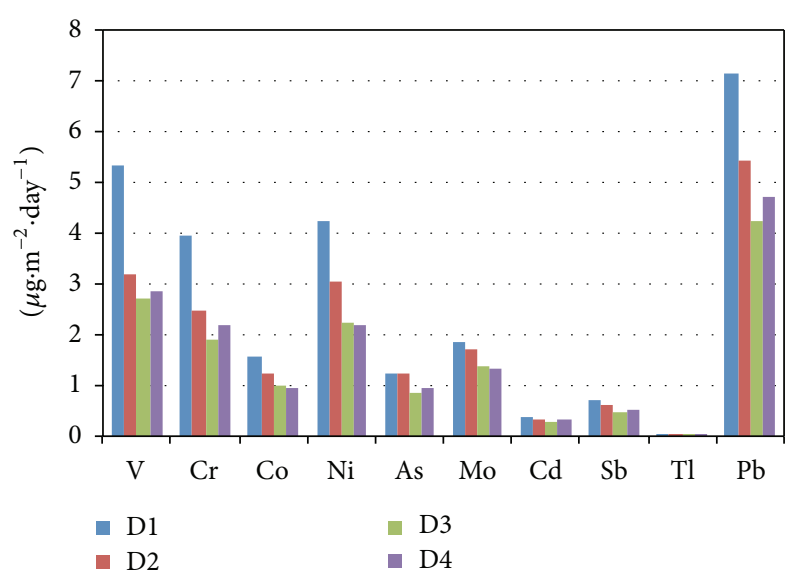

Figure 2: Average depositions of inorganic micropollutants for deposimeters D1, D2, D3, and D4 from January 2005 to May 2006.

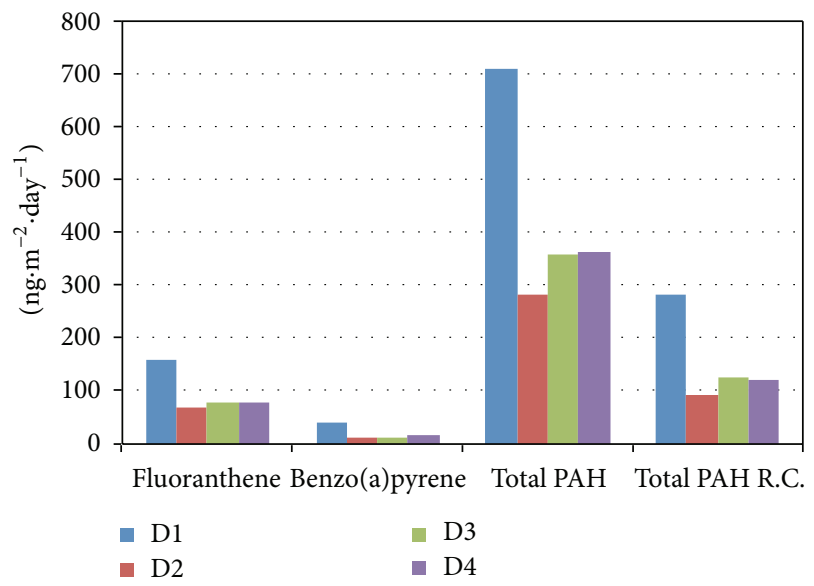

Figure 3: Average depositions of organic micropollutants for deposimeters D1, D2, D3, and D4 from January 2005 to May 2006.

impact of construction activities on atmospheric depositions appears strictly limited to the construction area.

Rossini et al. [8] analysed atmospheric bulk deposition from July 1998 to July 1999 in four different sites of the Venice Lagoon: one in the centre of the town (A), one almost near the industrial area of Porto Marghera (D), and two in more remote southern (C) and northern (B) areas of the Lagoon. If we compare Rossini's data to those reported in the present study (Table 1), we can see that they are quite similar. In particular, in D1, the average daily fluxes of vanadium, chromium, arsenic $\left(1 \pm 1 \mu \mathrm{g} \cdot \mathrm{m}^{-2} \cdot\right.$ day $\left.^{-1}\right)$, and total PAH are similar to those found by Rossini et al. in the urban site. Moreover, in D4, the average daily fluxes of vanadium, chromium $\left(2 \pm 1 \mu \mathrm{g} \cdot \mathrm{m}^{-2} \cdot \mathrm{day}^{-1}\right)$, nickel, cadmium, lead, and total PAH $\left(366 \pm 391 \mathrm{ng} \cdot \mathrm{m}^{-2} \cdot \mathrm{day}^{-1}\right)$ are similar to or lower than those found by Rossini et al. [8] in the remote areas of the Lagoon. This is reasonable considering the site D4 as reference for the surrounding area without impacts from the construction activities.

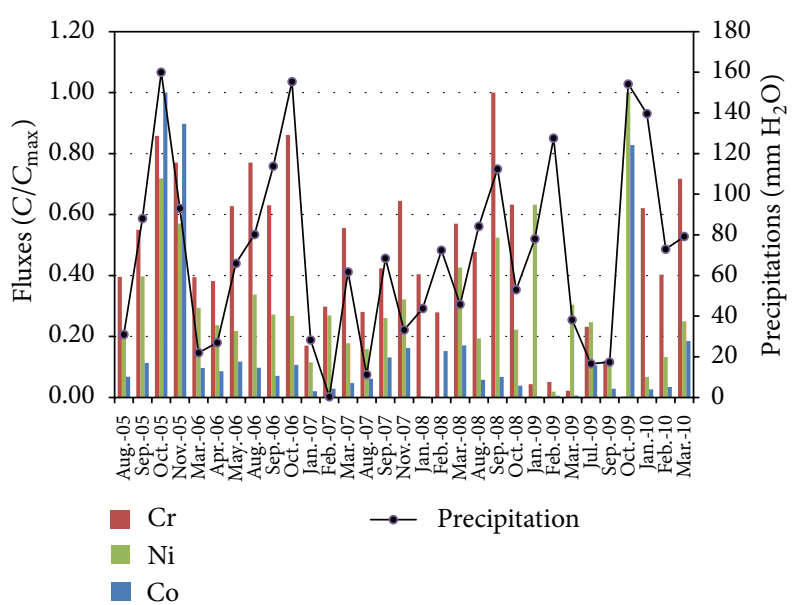

FIGURE 4: Fluxes of chromium, nickel, and cobalt and precipitations in D4 from August 2005 to March 2010.

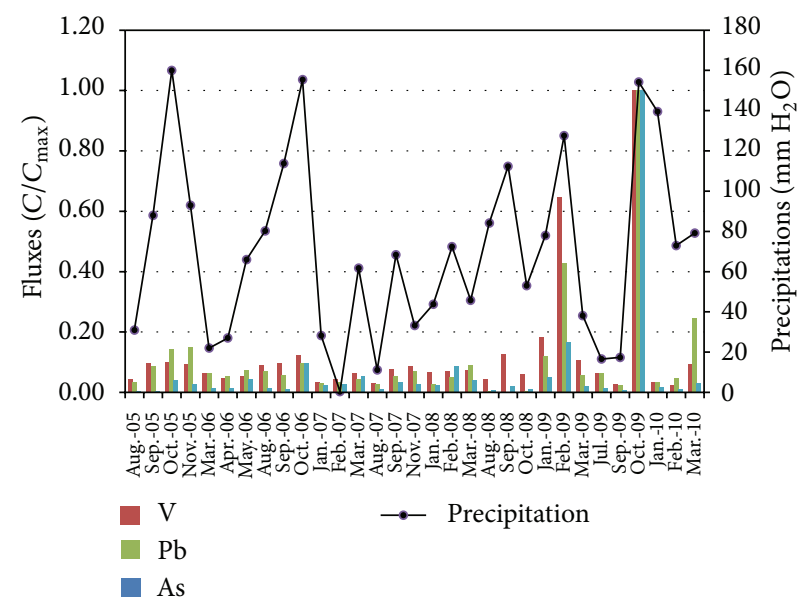

FIGURE 5: Fluxes of vanadium, lead, and arsenic and precipitations in D4 from August 2005 to March 2010.

The fluxes of pollutants determined in D4, expressed as $C / C_{\max }$, are reported alongside the precipitations (measured in $\mathrm{mm}$ of water) collected in the same site during the same sampling period. The diagrams for elements and organic pollutants are reported in Figures 4-9.

Behaviours of chromium, nickel, and cobalt are almost dependent on precipitations, as can be seen in Figure 4 . For chromium, moreover, there is no correspondence during two events in February and October 2009, when high precipitations occurred (128 and $154 \mathrm{~mm}$ of water, resp.). The agreement between the flux of cobalt and the precipitation is mainly due to two events which occurred in October 2005 and October 2009. The behaviour of these elements does not show any evident temporal trend. The temporal evolution of the flux of vanadium (Figure 5) measured in the D4 site shows no visible correlation with the precipitations, except for two events in February and October 2009, when the element's high fluxes $\left(28,4\right.$ and $\left.44 \mu \mathrm{g} \cdot \mathrm{m}^{-2} \cdot \mathrm{day}^{-1}\right)$ seem to be due to high precipitations. 
TABLE 1: Daily fluxes of inorganic elements $\left(\mu \mathrm{g} \cdot \mathrm{m}^{-2} \cdot \mathrm{day}^{-1}\right)$ and total PAH $\left(\mathrm{ng} \cdot \mathrm{m}^{-2} \cdot\right.$ day $\left.^{-1}\right)$ measured in this study and in Rossini et al.s study [8].

\begin{tabular}{|c|c|c|c|c|c|c|c|c|c|c|c|c|}
\hline & & As & $\mathrm{Cd}$ & $\mathrm{Cr}$ & $\mathrm{Cu}$ & $\mathrm{Fe}$ & $\mathrm{Ni}$ & $\mathrm{Pb}$ & $\mathrm{Sb}$ & $\mathrm{V}$ & $\mathrm{Zn}$ & $\sum \mathrm{PAH}$ \\
\hline \multirow{4}{*}{ D1 } & Average & 1.2 & 0.3 & 3.7 & & & 3.6 & 5.8 & 0.6 & 4.7 & & 676 \\
\hline & Std. dev. & 0.6 & 0.4 & 1.7 & & & 1.6 & 2.8 & 0.2 & 2.0 & & 788 \\
\hline & Min. & 0.3 & 0.0 & 1.1 & & & 1.0 & 2.9 & 0.3 & 1.9 & & 26 \\
\hline & Max. & 2.4 & 1.5 & 6.5 & & & 6.1 & 13.1 & 1.2 & 8.5 & & 2904 \\
\hline \multirow{4}{*}{ D4 } & Average & 3.1 & 0.4 & 1.9 & 15.9 & 1792 & 1.9 & 6.1 & 1.7 & 5.1 & 39.4 & 296 \\
\hline & Std. dev. & 9.0 & 0.8 & 1.1 & 22.9 & 3127 & 1.4 & 10.6 & 3.3 & 8.4 & 66.1 & 273 \\
\hline & Min. & 0.2 & 0.0 & 0.0 & 2.4 & 27 & 0.0 & 0.1 & 0.3 & 1.0 & 6.3 & 22 \\
\hline & Max. & 52.4 & 4.4 & 4.2 & 98.7 & 12890 & 6.7 & 59.8 & 15.1 & 44.0 & 277.2 & 1280 \\
\hline \multirow{4}{*}{ D5 } & Average & 3.1 & 0.5 & 4.5 & 15.6 & 2726 & 4.4 & 8.8 & 2.3 & 9.6 & 48.5 & 464 \\
\hline & Std. dev. & 3.1 & 1.0 & 4.9 & 25.3 & 3615 & 5.2 & 10.5 & 3.9 & 12.4 & 57.9 & 526 \\
\hline & Min. & 0.5 & 0.1 & 0.1 & 1.1 & 128 & 0.4 & 0.1 & 0.1 & 2.2 & 8.6 & 19 \\
\hline & Max. & 10.9 & 4.4 & 14.5 & 98.7 & 12890 & 9.2 & 59.8 & 15.1 & 44.0 & 277.2 & 1837 \\
\hline \multirow{4}{*}{ D6 } & Average & 2.6 & 0.2 & 8.9 & 7.5 & 2672 & 4.7 & 9.9 & 4.9 & 8.6 & 125.7 & 279 \\
\hline & Std. dev. & 2.5 & 0.5 & 7.7 & 7.5 & 3302 & 4.6 & 12.7 & 13.6 & 8.7 & 355.3 & 222 \\
\hline & Min. & 0.1 & 0.0 & 0.1 & 0.4 & 98 & 0.1 & 0.2 & 0.1 & 0.3 & 2.3 & 21 \\
\hline & Max. & 9.4 & 2.1 & 24.7 & 25.5 & 11831 & 14.6 & 46.4 & 57.5 & 29.8 & 1194.6 & 796 \\
\hline \multirow{4}{*}{ A [8] } & Average & 0.001 & 0.7 & 4.4 & 14.3 & 622 & 6.4 & 14.2 & 0.2 & 5.7 & 97.6 & 842 \\
\hline & Std. dev. & 0.4 & 0.9 & 1.6 & 6.4 & 386 & 2.4 & 4.5 & 0.2 & 2.2 & 59.8 & 518 \\
\hline & Min. & 0.4 & 0.2 & 2.2 & 6.6 & 203 & 3 & 8.2 & 0.0 & 2.7 & 25.5 & 288 \\
\hline & Max. & 1.9 & 3.5 & 7.8 & 29.3 & 1452 & 11.5 & 23.2 & 0.6 & 8.8 & 253.4 & 2035 \\
\hline \multirow{4}{*}{ B [8] } & Average & 0.6 & 0.2 & 1.7 & 8.8 & 361 & 2.8 & 5.8 & 0.1 & 4.1 & 54 & 271 \\
\hline & Std. dev. & 0.3 & 0.1 & 0.8 & 4.9 & 198 & 1.1 & 3.8 & 0.1 & 1.6 & 32.7 & 211 \\
\hline & Min. & 0.2 & 0.0 & 0.6 & 4.4 & 138 & 1.4 & 2.4 & 0.01 & 2.1 & 9.5 & 18 \\
\hline & Max. & 1.3 & 0.5 & 3.5 & 18.8 & 829 & 5.2 & 13.5 & 0.3 & 7.4 & 118.5 & 633 \\
\hline \multirow{4}{*}{ C [8] } & Average & 0.6 & 0.4 & 3.0 & 10.1 & 536 & 4.5 & 11 & 0.2 & 6 & 69.3 & 286 \\
\hline & Std. dev. & 0.2 & 0.5 & 1.2 & 4.7 & 303 & 1.8 & 3.5 & 0.2 & 3.9 & 53.6 & 236 \\
\hline & Min. & 0.2 & 0.1 & 0.8 & 4.9 & 268 & 1.9 & 6.1 & 0.0 & 2.1 & 19 & 32 \\
\hline & Max. & 0.9 & 2.0 & 5.5 & 18.5 & 1275 & 8.1 & 19.2 & 0.6 & 15.9 & 212.4 & 659 \\
\hline \multirow{4}{*}{$\mathrm{D}[8]$} & Average & 0.8 & 0.3 & 3.4 & 12.7 & 446 & 6.9 & 7.6 & 0.1 & 8 & 96.7 & 1029 \\
\hline & Std. dev. & 0.3 & 0.5 & 2.3 & 11 & 272 & 2.4 & 3.9 & 0.2 & 2.8 & 71 & 844 \\
\hline & Min. & 0.4 & 0.1 & 0.4 & 6.1 & 85 & 3.2 & 1.9 & 0.01 & 3.9 & 19.2 & 77 \\
\hline & Max. & 1.4 & 2.0 & 6.5 & 47.5 & 849 & 11.9 & 14.2 & 0.4 & 12.5 & 250.5 & 3352 \\
\hline
\end{tabular}

A: city of Venice; B: northern Lagoon; C: southern Lagoon; D: Porto Marghera.

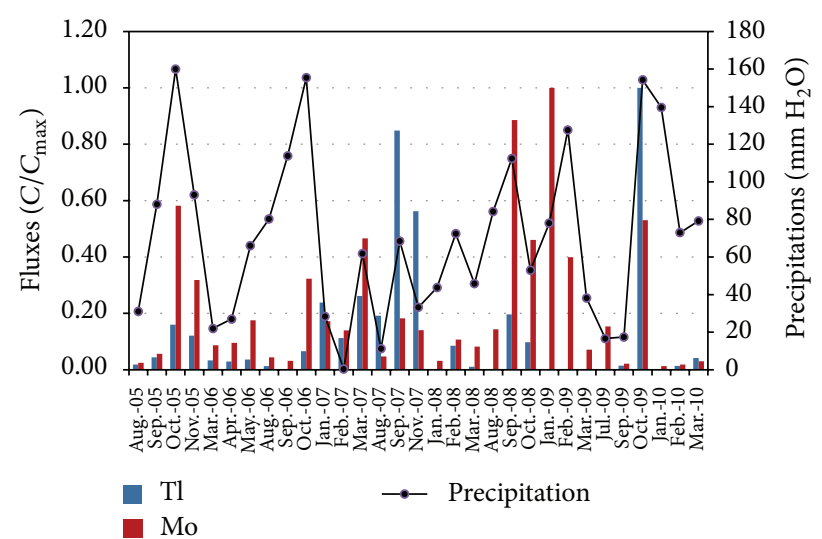

FIGURE 6: Fluxes of thallium and molybdenum and precipitations in D4 from August 2005 to March 2010.
A seasonal trend is more evident, with higher concentrations measured during the autumnal months.

In October 2009, a peak was registered in the concentration of most of elements, as nickel, cobalt, (Figure 4), vanadium, lead, arsenic (Figure 5), thallium, molybdenum (Figure 6), and antimony (Figure 7), but not for organic pollutants.

In the cases of arsenic, lead, and vanadium, the concentration measured in October 2009 is one order of magnitude higher than the average concentration of the whole temporal series.

We can also notice a light seasonal trend, with higher concentrations in the autumnal-winter months, for vanadium, lead, arsenic (Figure 5), cadmium, and antimony (Figure 7).

At last, molybdenum and thallium show a temporal trend that seems to depend on both precipitations and seasons (Figure 6). 


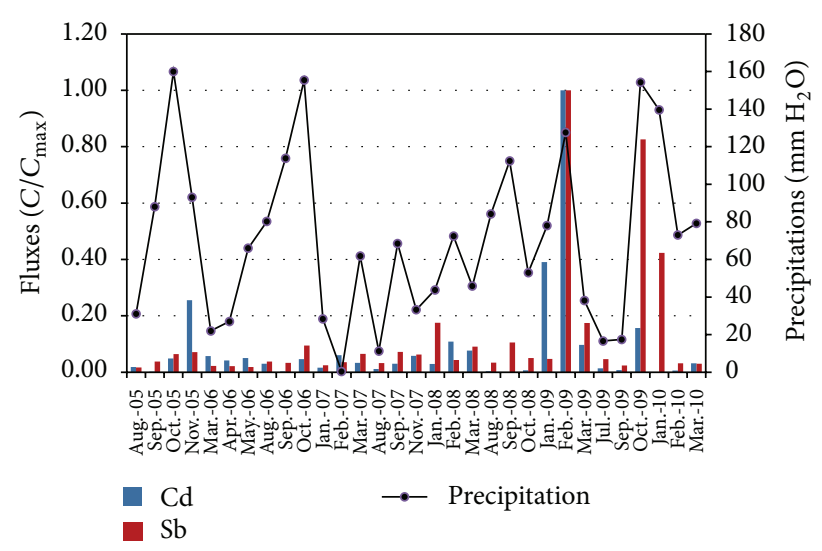

FIgURE 7: Fluxes of cadmium and antimony and precipitations in D4 from August 2005 to March 2010.

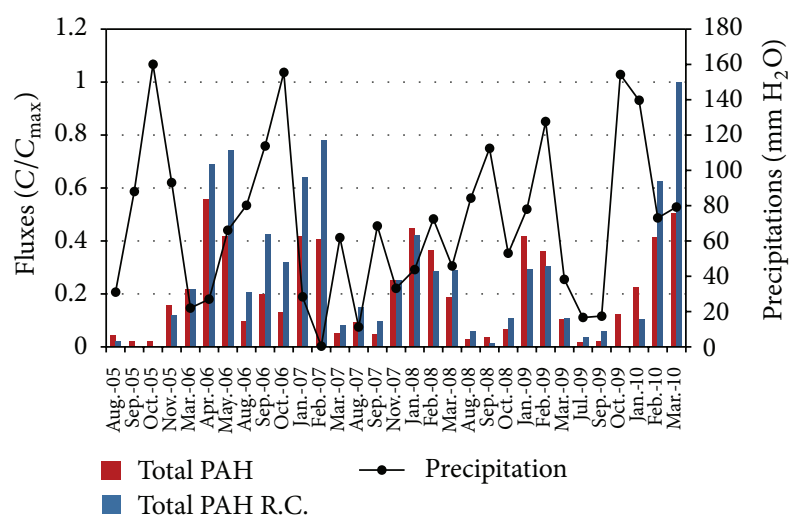

Figure 8: Fluxes of total PAH and total PAH R.C. and precipitations in D4 from August 2005 to March 2010.

As for organic compounds, the seasonal trend is clearly visible for the total PAH (Figure 8) and fluoranthene (Figure 9), with peaks in late winter-early spring. The same seasonal trend is also present, but less visibly so, for the $\mathrm{PAH}$ involving a cancer risk (total PAH R.C., Figure 8). Benzo(a)pyrene shows no evident trend (Figure 9).

None of these pollutants, whether inorganic or organic, present any long-term trend. The dataset shows neither an increase nor a decrease over the years. In order to better define the role of precipitations in the flux of pollutants, we compared their average flux under three different precipitation conditions: less than $40 \mathrm{~mm}$ of water, between 40 and $80 \mathrm{~mm}$, and more than $80 \mathrm{~mm}$.

The diagrams of the average flux for each pollutant in the three pluviometrical series are reported in Figures 10 and 11 for inorganic and organic pollutants, respectively.

We can notice that the average fluxes of the elements during abundant precipitations (green series) are significantly higher than those during lower precipitations, in particular for vanadium, arsenic, antimony, and lead: these peaks are due to specific events, as previously observed, that occurred during 2009. For other elements, such as chromium, cobalt, nickel, and cadmium, the trend is more regular, emphasizing

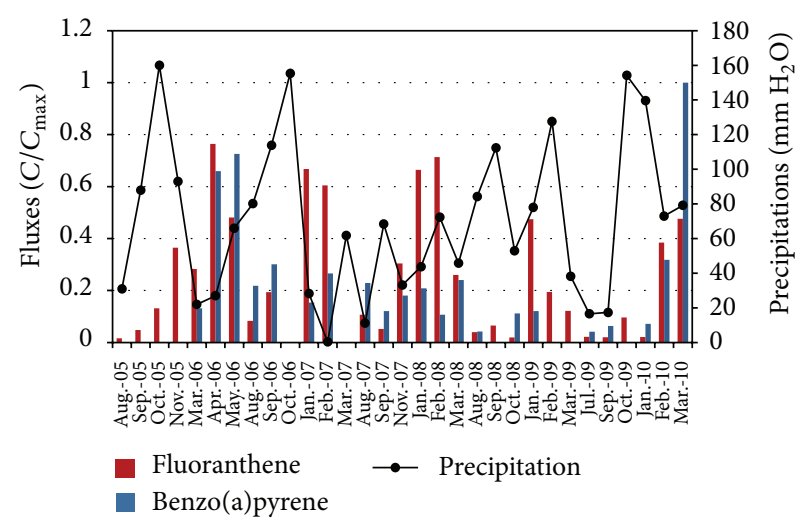

FIGURE 9: Fluxes of fluoranthene and benzo(a)pyrene and precipitations in D4 from August 2005 to March 2010.

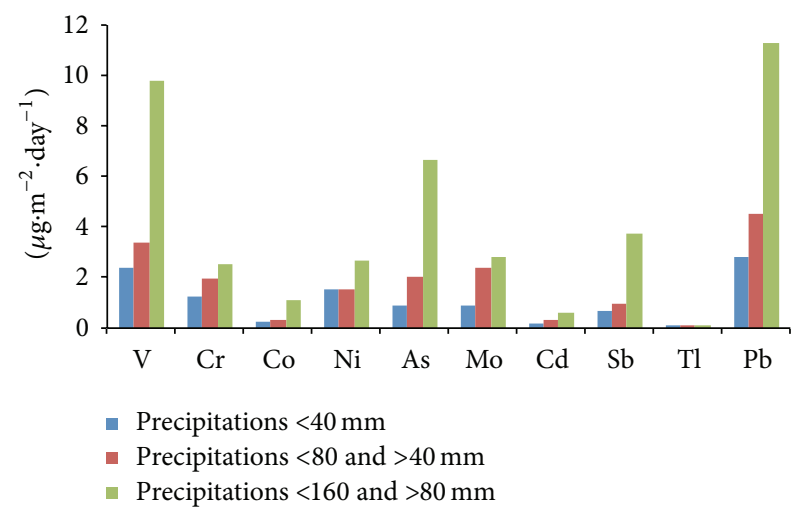

FIGURE 10: Average depositions of inorganic micropollutants for deposimeters D4 grouped according to precipitations.

the high correlations between their fluxes and the precipitation (Figure 10).

For organic pollutants, except for fluoranthene, the highest concentrations were observed during precipitations of medium intensity, showing the low correlation with their fluxes and precipitations (Figure 11). It should be noted that the low fluxes of organic compounds during high precipitations could be due to a correlation induced by the seasonal trends. Spring and summer atmospheric concentrations (and fluxes) of PAHs are lower because of the higher solar radiation and temperature. These conditions are generally associated with lower precipitations.

To better understand the relation between these variables, we performed a PCA analysis on the matrix constituted by fluxes determined in the $\mathrm{D} 4$ site. As variables, we used the precipitations and the daily fluxes of inorganic (As, Cd, Co, $\mathrm{Cr}, \mathrm{Mo}, \mathrm{Ni}, \mathrm{Pb}, \mathrm{Sb}$, and $\mathrm{V}$ ) and organic compounds (Fluo, $\sum$ PAH, and $\sum$ PAH R.C.). We omitted from our statistical analysis those elements and organic compounds that were often under the detection limit.

The first component accounts for $41,66 \%$ of the total variance, the second for $20,93 \%$, and the third for $12,39 \%$ : total variance measured in the first three principal components is equal to $75 \%$. From the scores plot (Figure 12) of the 


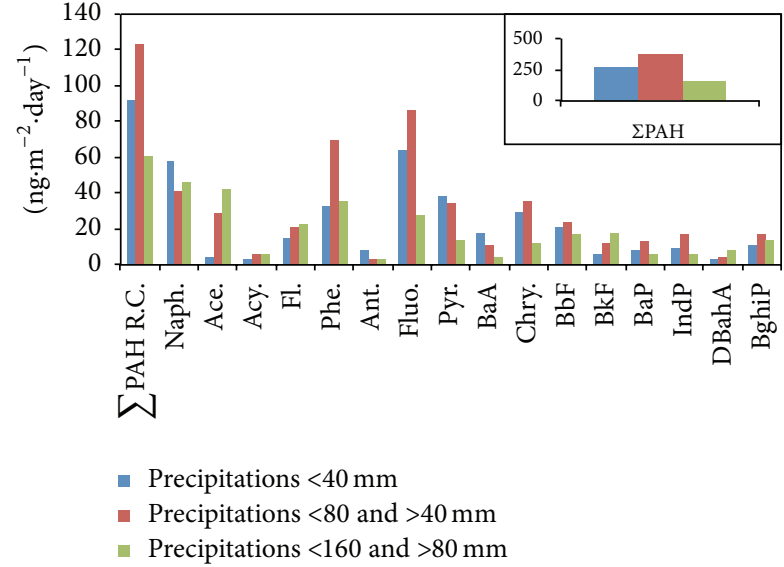

FIgURE 11: Average depositions of organic micropollutants for deposimeters D4 grouped according to precipitations. Total IPA concentrations are reported separately because of different scale.

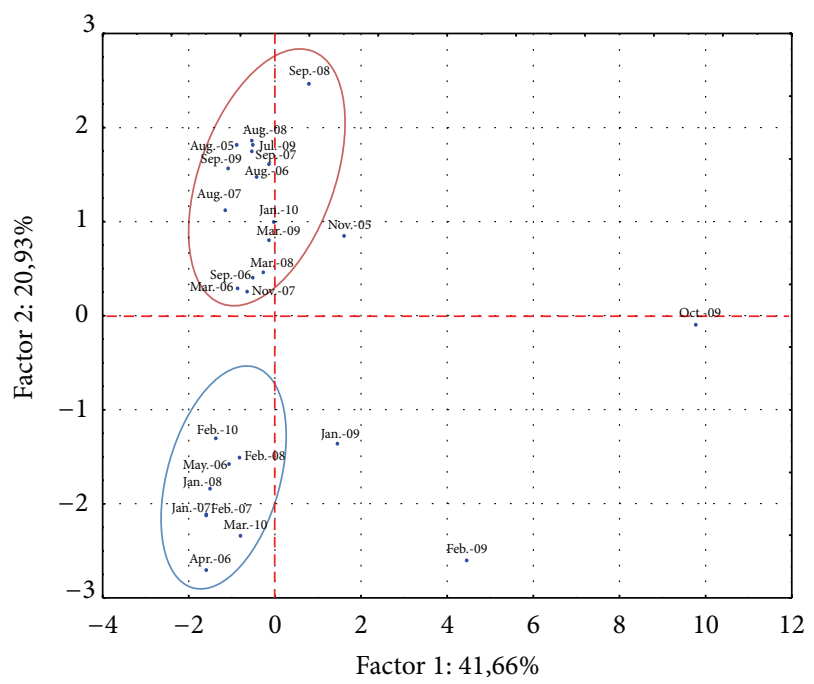

FIGURE 12: Score plot of the two first principal components obtained by PCA analysis of fluxes determined in D4.

first versus the second principal components, two distinct groups can be identified, divided by the second principal component: one contains all the fluxes measured during summer and autumn (red circle); the other contains most of the fluxes measured during winter (blue circle). Samples collected during spring are not placed in an individual group. From the loadings plot (Figure 13) it is possible to see that the distinction between summer-autumn and winter samples is due to variances in the organic compounds, in particular with regard to the total PAH, total PAH R.C., and fluoranthene. This distinction is in agreement with previous analyses: organic compounds have a seasonal trend, independently of the precipitations. The latter variable is mostly correlated with inorganic elements. In the scores plot, the samples of January and October 2009 (Jan.-09 and Oct.-09) are separated from the others by the first principal component and this happens mainly because of the precipitation and the concentrations of

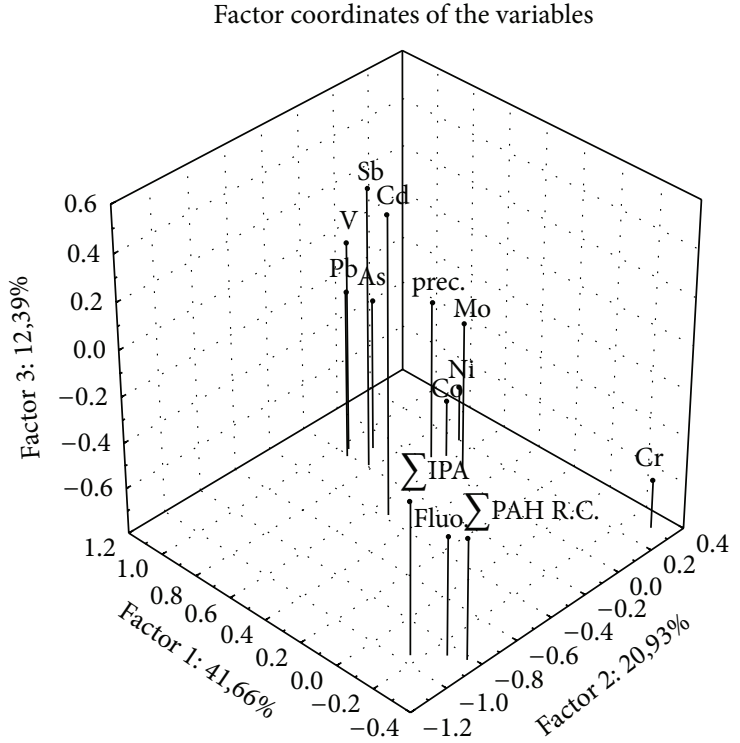

FIGURE 13: Loading plot 3D of the three first principal components obtained by PCA analysis of fluxes determined in D4.

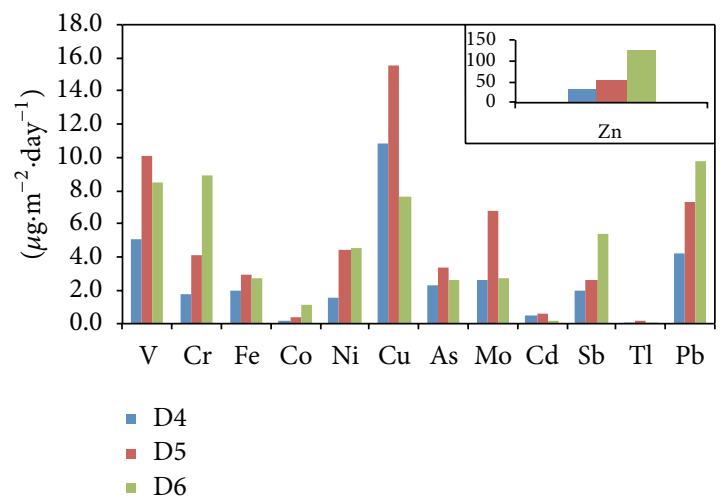

FIGURE 14: Average depositions of inorganic micropollutants for deposimeters D4, D5, and D6 from September 2006 to March 2009. Iron concentrations are in $\mathrm{mg} \cdot \mathrm{m}^{-2} \cdot \mathrm{day}^{-1}$. Zinc concentrations are reported separately because of different scale.

$\mathrm{As}, \mathrm{Cd}, \mathrm{Pb}, \mathrm{Sb}$, and $\mathrm{V}$ (see Figure 2). Interestingly, $\mathrm{Cr}$, Co, and $\mathrm{Ni}$ are separated from other inorganic elements.

In order to investigate the spatial difference between fluxes of contaminants, three different sites placed at the three inlets of the Venice Lagoon were simultaneously sampled from September 2006 to March 2009: the previously mentioned D4 site, next to the Lido inlet in the north of the Lagoon, the D5 site next to the Malamocco inlet in the middle-south of the Lagoon, and the D6 site placed next to the Chioggia inlet in the north of the Lagoon (Figure 1).

Figures 14 and 15 report the average daily fluxes of inorganic and organic contaminants in the three sites during the simultaneous sampling.

Average daily fluxes reported in the D4 site, which were placed in the northern Venice Lagoon, are lower than those in other sites for all the elements and organic pollutants 


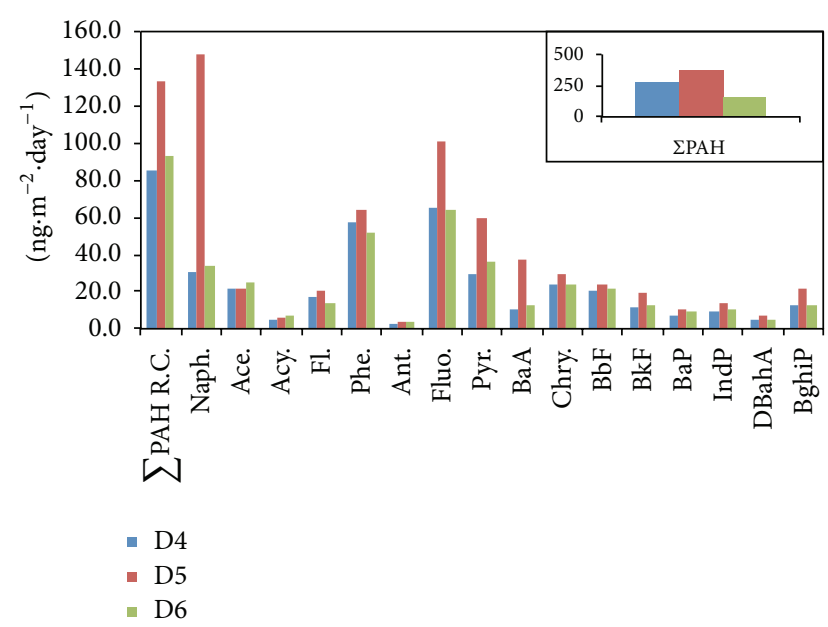

FIGURE 15: Average depositions of organic micropollutants for deposimeters D4, D5, and D6 from September 2006 to March 2009. Total IPA concentrations are reported separately because of different scale.

analysed. The site next to the Malamocco inlet presents a higher flux not only of copper $\left(16 \pm 25 \mu \mathrm{g} \cdot \mathrm{m}^{-2} \cdot \mathrm{day}^{-1}\right)$ and molybdenum $\left(7 \pm 12 \mu \mathrm{g} \cdot \mathrm{m}^{-2} \cdot \mathrm{day}^{-1}\right)$ but also of vanadium $\left(10 \pm 12 \mu \mathrm{g} \cdot \mathrm{m}^{-2} \cdot \mathrm{day}^{-1}\right)$, iron $\left(3 \pm 4 \mathrm{mg} \cdot \mathrm{m}^{-2} \cdot \mathrm{day}^{-1}\right)$, and arsenic $\left(3 \pm 3 \mu \mathrm{g} \cdot \mathrm{m}^{-2} \cdot \mathrm{day}^{-1}\right)$. As for organic pollutants, the average daily fluxes found in the Malamocco inlet site are the highest, in particular for naphthalene (148 \pm $\left.280 \mathrm{ng} \cdot \mathrm{m}^{-2} \cdot \mathrm{day}^{-1}\right)$, fluoranthene $\left(101 \pm 140 \mathrm{ng} \cdot \mathrm{m}^{-2} \cdot \mathrm{day}^{-1}\right)$, and total PAH $\left(464 \pm 526 \mathrm{ng} \cdot \mathrm{m}^{-2} \cdot \mathrm{day}^{-1}\right)$.

The D6 site next to the Chioggia inlet presents high fluxes of chromium $\left(9 \pm 8 \mu \mathrm{g} \cdot \mathrm{m}^{-2} \cdot \mathrm{day}^{-1}\right)$, cobalt $(1 \pm$ $1 \mu \mathrm{g} \cdot \mathrm{m}^{-2} \cdot$ day $\left.^{-1}\right)$, zinc $\left(126 \pm 355 \mu \mathrm{g} \cdot \mathrm{m}^{-2} \cdot\right.$ day $\left.^{-1}\right)$, antimony $\left(5 \pm 14 \mu \mathrm{g} \cdot \mathrm{m}^{-2} \cdot \mathrm{day}^{-1}\right)$, and lead $\left(10 \pm 13 \mu \mathrm{g} \cdot \mathrm{m}^{-2} \cdot \mathrm{day}^{-1}\right)$.

Our D6 results were also compared to those reported by Rossini et al. [8] during 1998-1999 in the site C (also placed in the southern part of the Lagoon, but on the mainland). Our results for chromium, iron, arsenic, and antimony are higher than those of Rossini et al. [8]. In particular, the flux of iron determined in D6 is six times higher than the flux determined in the site C, while, for other elements, the fluxes found in D6 and in site $\mathrm{C}$ are almost comparable (see also Table 1).

As for PAHs, the fluxes determined in D6 are much lower than those observed in site $\mathrm{C}$, but comparable to the data reported by Rossini et al. [9] from March 2003 to March 2004.

Fluxes of pollutants in the southern area of the Lagoon are comparable with the data reported in other studies $[8,9,11]$ for atmospheres more contaminated. In terms of atmospheric pollution, the southern Lagoon shows traces of the influence of other sources, like the nearby city of Chioggia and the Po Valley.

In the D5 site, next to the Malamocco inlet, higher fluxes of organic pollutants were determined. This is most probably due to the use of fuel in powerboats, which circulate mainly in the central area of the Lagoon and especially in the city centre. The site with the lowest fluxes was the one located in
TABLE 2: Concentrations $\left(\mathrm{ng} / \mathrm{m}^{3}\right)$ of elements in PM10 measured in the three sites [4].

\begin{tabular}{|c|c|c|c|c|}
\hline & & P. Sabbioni & Chioggia & Malamocco \\
\hline \multirow{2}{*}{ V } & Aver & 4.40 & 4.40 & 5.60 \\
\hline & $(\min$ & $(0.3-15.3)$ & $(0.3-15.7)$ & $(0.1-18.1)$ \\
\hline \multirow{2}{*}{$\mathrm{Cr}$} & Ave & 5.20 & 4.00 & 3.80 \\
\hline & (min. & $(0.4-21.9)$ & $(0.4-72.1)$ & $(0.4-12.4)$ \\
\hline \multirow{2}{*}{$\mathrm{Fe}$} & Average & 357.00 & 394.40 & 319.60 \\
\hline & (min.-max.) & $(24.3-1347.3)$ & $(30.2-$ & $(13.0-941.3)$ \\
\hline \multirow{2}{*}{ Co } & Average & 0.20 & & 0.20 \\
\hline & (min.-max.) & $(0.01-2.2)$ & & $(0.03-1.0)$ \\
\hline \multirow{2}{*}{$\mathrm{Ni}$} & Average & 3.90 & 3.50 & 4.60 \\
\hline & (min.-max.) & $(0.2-18.3)$ & $(0.3-28.7)$ & $(0.5-17.0)$ \\
\hline \multirow{2}{*}{$\mathrm{Cu}$} & Average & 9.80 & 6.40 & 8.90 \\
\hline & (min.-max. & $(0.5-43.2)$ & $(0.5-30.8)$ & $(0.2-28.8)$ \\
\hline \multirow{2}{*}{$\mathrm{Zn}$} & Average & 57.40 & 33.00 & 43.00 \\
\hline & (min.-max.) & $(1.1-177.3)$ & $(0.3-102.8)$ & $(1.3-129.6)$ \\
\hline \multirow{2}{*}{ As } & Average & 2.00 & 1.10 & 2.10 \\
\hline & (min.-max.) & $(0.1-13.3)$ & $(0.1-6.1)$ & $(0.1-13.9)$ \\
\hline \multirow{2}{*}{ Cd } & Average & 2.20 & 1.50 & 2.70 \\
\hline & (min.-max.) & $(0.01-20.7)$ & $(0.01-13.2)$ & $(0.01-35.6)$ \\
\hline \multirow{2}{*}{$\mathrm{Sb}$} & Average & 8.60 & 4.70 & 7.30 \\
\hline & (min.-max.) & $(0.6-35.9)$ & $(0.1-53.7)$ & $(0.2-34.5)$ \\
\hline \multirow{2}{*}{$\mathrm{Tl}$} & Average & 0.06 & & \\
\hline & (min.-max.) & $(0.001-0.5)$ & & \\
\hline \multirow{2}{*}{$\mathrm{Pb}$} & Average & 21.30 & 16.10 & 21.20 \\
\hline & $(\min .-\max )$. & $(1.6-161.8)$ & $(0.5-93.1)$ & $(0.8-325.1)$ \\
\hline
\end{tabular}

the northern part of the Lagoon, as also found by Rossini et al. [8].

As inorganic elements are concerned, we try to make a comparison between fluxes of contaminants in the three sites of the Lagoon and results obtained by a study carried out in the same sites, from 2007 to 2010, related to the concentrations of pollutants in PM10 [4].

In Table 2 are reported the concentrations of elements (average, min., and max.) resulting in this study. As observed in this study for the fluxes, elements with higher concentration were iron, zinc, copper, and lead. Considering the spatial distribution, the elements concentrations in PM10 in the site of Chioggia were lower than those in the other two sites. Anyway, the distribution of contaminants transported by PM10 seems to be more homogeneous than that observed in our study for the fluxes.

We performed a PCA statistical analysis on a matrix constituted by the fluxes of inorganic elements (As, Cd, Co, $\mathrm{Cr}, \mathrm{Mo}, \mathrm{Ni}, \mathrm{Pb}, \mathrm{Sb}$, and $\mathrm{V})$, organic compounds ( $\sum \mathrm{PAH}$ and $\sum$ PAH R.C.), and precipitations in the three different sites, with the aim of understanding if there is a geographic separation and the variables involved in it.

The first component accounts for $37,33 \%$ of the total variance, the second for $18,33 \%$, and the third for $15,22 \%$ : total variance measured in the first three principal components is equal to $70,9 \%$. 


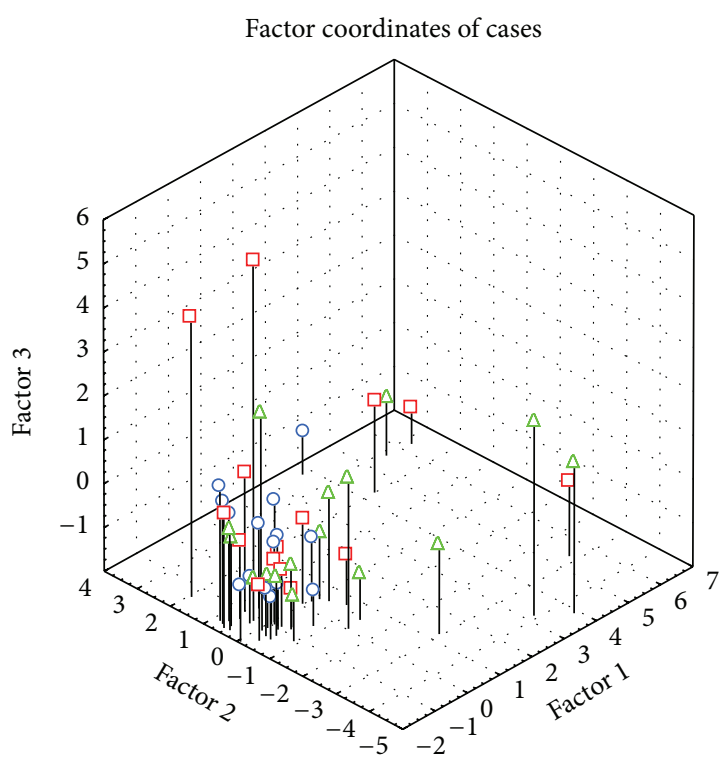

FIGURE 16: Score plot 3D of the three first principal components obtained by PCA analysis of fluxes collected in D4 (O), D5 ( $\square$ ), and D6 $(\Delta)$ from September 2006 to March 2009.

Table 3 reports the factor coordinates of the variables, based on correlations, of the first three factors, and Figure 16 reports the score plot $3 \mathrm{D}$ of the three first principal components. In the first component are grouped the most parts of inorganic elements ( $\mathrm{V}, \mathrm{Ni}, \mathrm{As}, \mathrm{Mo}, \mathrm{Cd}, \mathrm{Sb}$, and $\mathrm{Pb}$ ), while in the third component are grouped the two organic variables. $\mathrm{Cr}$ and $\mathrm{Co}$ are separated from the others, as observed previously, and contribute on the second component.

Samples collected in the D4 site (blue circles) are all grouped. The other two sites (red squares for Malamocco and green triangles for Chioggia) have many samples separated from the others because of Factor 1 (in particular V, Ni, As, and $\mathrm{Cd}$,) and Factor 3 (organic compounds). The statistical analysis performed on the three sites confirms what emerged above, namely, that the D4 site presents the most regular fluxes, while the other sites are characterised by several peaks in the fluxes of pollutants.

\section{Conclusions}

The aim of the present work was investigating the spatial variability of depositions in the Venice Lagoon, its correlation with precipitations, and the possible impact of the construction of the MOSE dams, by studying the fluxes of inorganic and organic pollutants in the areas next to the construction sites. The contribution of the MOSE construction activities to the atmospheric depositions at the Lido inlet was studied through a chemical analysis of depositions simultaneously collected in four different deposimeters placed at different distances from the construction site, from January 2005 to May 2006. The fluxes measured in the inner area of the yard were comparable with fluxes found in the central Lagoon during other studies, while fluxes measured in deposimeters far from the yard were comparable with those found in
TABLE 3: Factor coordinates of the variables, based on correlation, of the first three factors obtained by PCA analysis of fluxes collected in D4, D5, and D6 from September 2006 to March 2009.

\begin{tabular}{lccc}
\hline Variable & Factor 1 & Factor 2 & Factor 3 \\
\hline $\mathrm{V}$ & $0.951^{*}$ & 0.021 & 0.009 \\
$\mathrm{Cr}$ & 0.528 & $-0.685^{*}$ & 0.249 \\
$\mathrm{Co}$ & 0.416 & $-0.799^{*}$ & 0.290 \\
$\mathrm{Ni}$ & $0.847^{*}$ & -0.357 & 0.112 \\
$\mathrm{As}$ & $0.741^{*}$ & 0.341 & -0.157 \\
$\mathrm{Mo}$ & $0.619^{*}$ & 0.028 & -0.218 \\
$\mathrm{Cd}$ & $0.694^{*}$ & 0.584 & -0.166 \\
$\mathrm{Sb}$ & $0.547^{*}$ & 0.400 & -0.140 \\
$\mathrm{~Pb}$ & $0.583^{*}$ & 0.214 & 0.066 \\
$\mathrm{NPAH}$ & 0.110 & 0.444 & $0.840^{*}$ \\
$\Sigma \mathrm{PAH} \mathrm{R.C.}$ & -0.023 & 0.286 & $0.915^{*}$ \\
Prec. & $0.584^{*}$ & -0.146 & -0.039 \\
\hline
\end{tabular}

*indicates which variable is important for the factor 1,2 or 3 .

remote areas of the Lagoon. The characterization of bulk depositions, with respect to inorganic elements and organic compounds, did not show evidence of any inverse correlation between element concentration and the distance from the construction site. The impact of construction activities on atmospheric depositions appears strictly limited to the construction area.

Pollutants had different temporal trends and a different correlation with the precipitations, as shown by temporal trends and statistical analysis via PCA. In particular, nickel, chromium, and cobalt had fluxes strictly influenced by precipitation; elements such as arsenic, lead, and vanadium showed behaviour partially connected with precipitations, mostly due to particular events with abundant precipitations. The temporal trend of other elements, such as antimony, cadmium, molybdenum, and thallium, did not show any evident correlation with precipitation or season, but rather behaviour influenced by multiple factors. Organic compounds showed, on the contrary, a seasonal temporal trend, with peaks occurring during late winter-early spring.

Moreover, for all pollutants here reported, both inorganic and organic, we cannot observe any long-term trend and neither an increase nor a decrease over the years has been put in evidence in the dataset.

The spatial distribution of contaminants' fluxes highlighted that the area next to the Lido inlet (northern Lagoon) had lower and almost homogeneous fluxes of contaminants, while, in the other sites placed next to the Malamocco and Chioggia inlets, contaminants' fluxes were more variable. The southern Lagoon showed traces of the influence of other sources, like the nearby city of Chioggia and the Po Valley. In the site close to the Malamocco inlet, higher fluxes of organic pollutants were determined. This is most probably due to the use of fuel in the powerboats, which circulate mainly in the central area of the Lagoon and especially in the city centre.

\section{Conflict of Interests}

The authors declare that there is no conflict of interests regarding the publication of this paper. 


\section{Acknowledgments}

This work was supported by the Ministero delle Infrastrutture e dei Trasporti Magistrato alle Acque di Venezia (Italian Ministry of Infrastructure and Transport, Venice Water Authority) through its dealer Consorzio Venezia Nuova. The authors wish to thank the Venice Water Authority for permission to use the data and CORILA (Consortium for Managing the Research Activities Concerning the Venice Lagoon System) for the valuable assistance and logistic support during the sampling campaigns. The authors would like to thank Daniela Almansi (Department of Environmental Sciences, Informatics and Statistics, Ca' Foscari University, Venice, Italy) for the English revision of the paper.

\section{References}

[1] S. Guerzoni, R. Chester, F. Dulac et al., "The role of atmospheric deposition in the biogeochemistry of the Mediterranean Sea," Progress in Oceanography, vol. 44, no. 1-3, pp. 147-190, 1999.

[2] A. I. Calvo, F. J. Olmo, H. Lyamani et al., "Chemical composition of wet precipitation at the background EMEP station in Víznar (Granada, Spain) (2002-2006)," Atmospheric Research, vol. 96, no. 2-3, pp. 408-420, 2010.

[3] P. S. M. Santos, E. B. H. Santos, and A. C. Duarte, "Seasonal and air mass trajectory effects on dissolved organic matter of bulk deposition at a coastal town in South-Western Europe," Environmental Science and Pollution Research, vol. 20, no. 1, pp. 227-237, 2013.

[4] D. Contini, F. Belosi, A. Gambaro, D. Cesari, A. M. Stortini, and M. C. Bove, "Comparison of PM10 concentrations and metal content in three different sites of the Venice Lagoon: an analysis of possible aerosol sources," Journal of Environmental Sciences, vol. 24, no. 11, pp. 1954-1965, 2012.

[5] A. Gambaro, L. Manodori, I. Moret, G. Capodaglio, and P. Cescon, "Determination of polychlorobiphenyls and polycyclic aromatic hydrocarbons in the atmospheric aerosol of the Venice Lagoon," Analytical and Bioanalytical Chemistry, vol. 378, no. 7, pp. 1806-1814, 2004.

[6] F. Prodi, F. Belosi, D. Contini et al., "Aerosol fine fraction in the Venice Lagoon: particle composition and sources," Atmospheric Research, vol. 92, no. 2, pp. 141-150, 2009.

[7] S. Guerzoni, G. Rampazzo, E. Molinaroli, and P. Rossini, "Atmospheric bulk deposition to the Lagoon of Venice: part II. Source apportionment analysis near the industrial zone of Porto Marghera, Italy," Environment International, vol. 31, no. 7, pp. 975-982, 2005.

[8] P. Rossini, S. Guerzoni, E. Molinaroli, G. Rampazzo, A. de Lazzari, and A. Zancanaro, "Atmospheric bulk deposition to the lagoon of Venice: part I. Fluxes of metals, nutrients and organic contaminants," Environment International, vol. 31, no. 7, pp. 959-974, 2005.

[9] P. Rossini, S. Guerzoni, G. Matteucci, M. Gattolin, G. Ferrari, and S. Raccanelli, "Atmospheric fall-out of POPs (PCDD-Fs, PCBs, HCB, PAHs) around the industrial district of Porto Marghera, Italy," Science of the Total Environment, vol. 349, no. 1-3, pp. 190-200, 2005.

[10] S. Guerzoni, P. Rossini, A. Sarretta, S. Raccanelli, G. Ferrari, and E. Molinaroli, "POPs in the Lagoon of Venice: budgets and pathways," Chemosphere, vol. 67, no. 9, pp. 1776-1785, 2007.
[11] A. Gambaro, M. Radaelli, R. Piazza et al., "Organic micropollutants in wet and dry depositions in the Venice Lagoon," Chemosphere, vol. 76, no. 8, pp. 1017-1022, 2009.

[12] A. M. Stortini, A. Freda, D. Cesari et al., "An evaluation of the $\mathrm{PM}_{2.5}$ trace elemental composition in the Venice Lagoon area and an analysis of the possible sources," Atmospheric Environment, vol. 43, no. 40, pp. 6296-6304, 2009. 

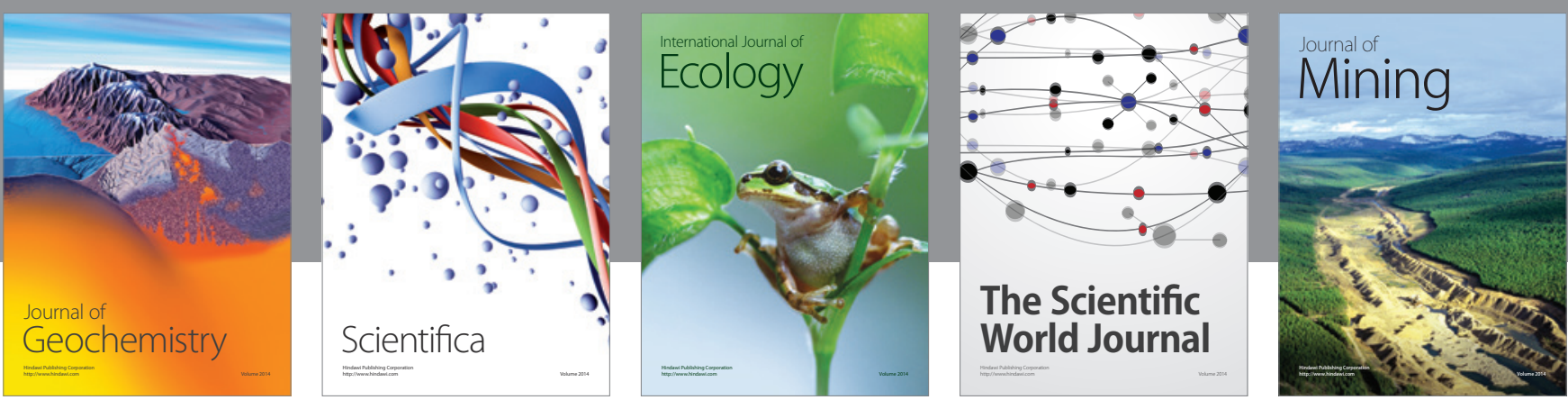

The Scientific World Journal
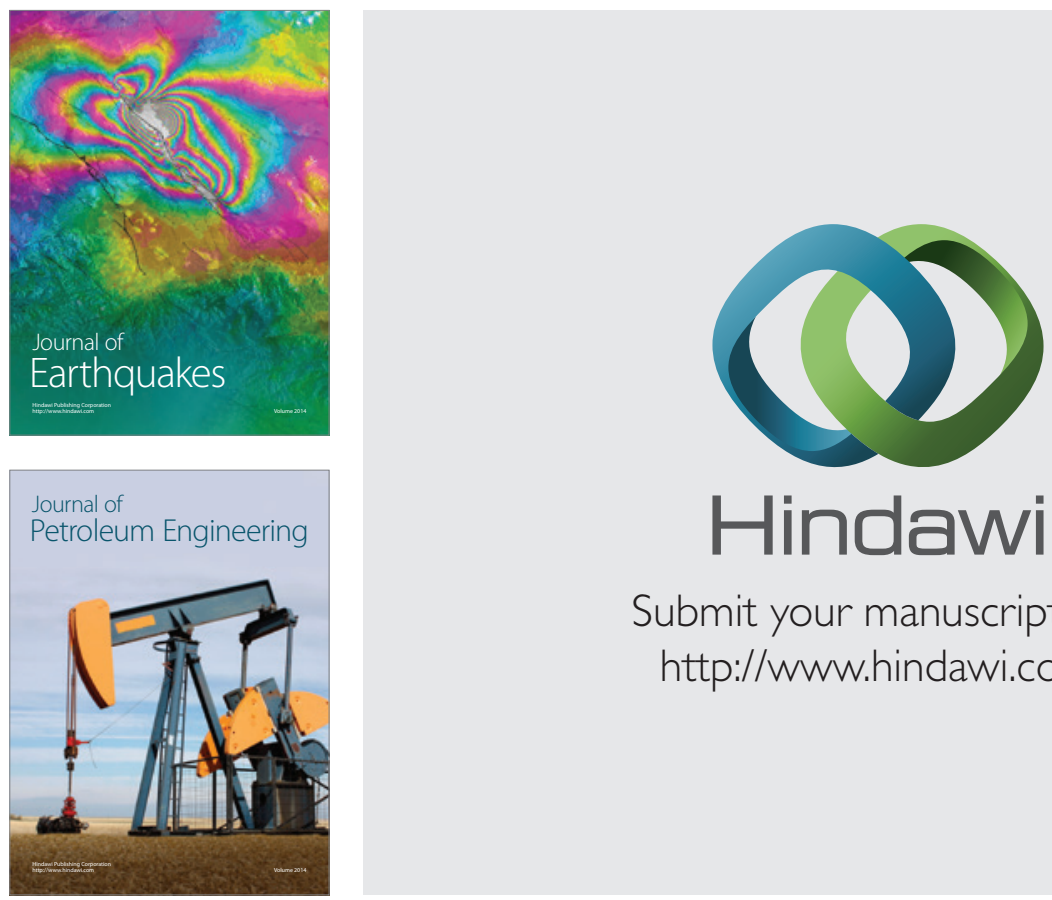

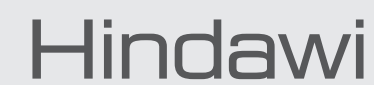

Submit your manuscripts at

http://www.hindawi.com
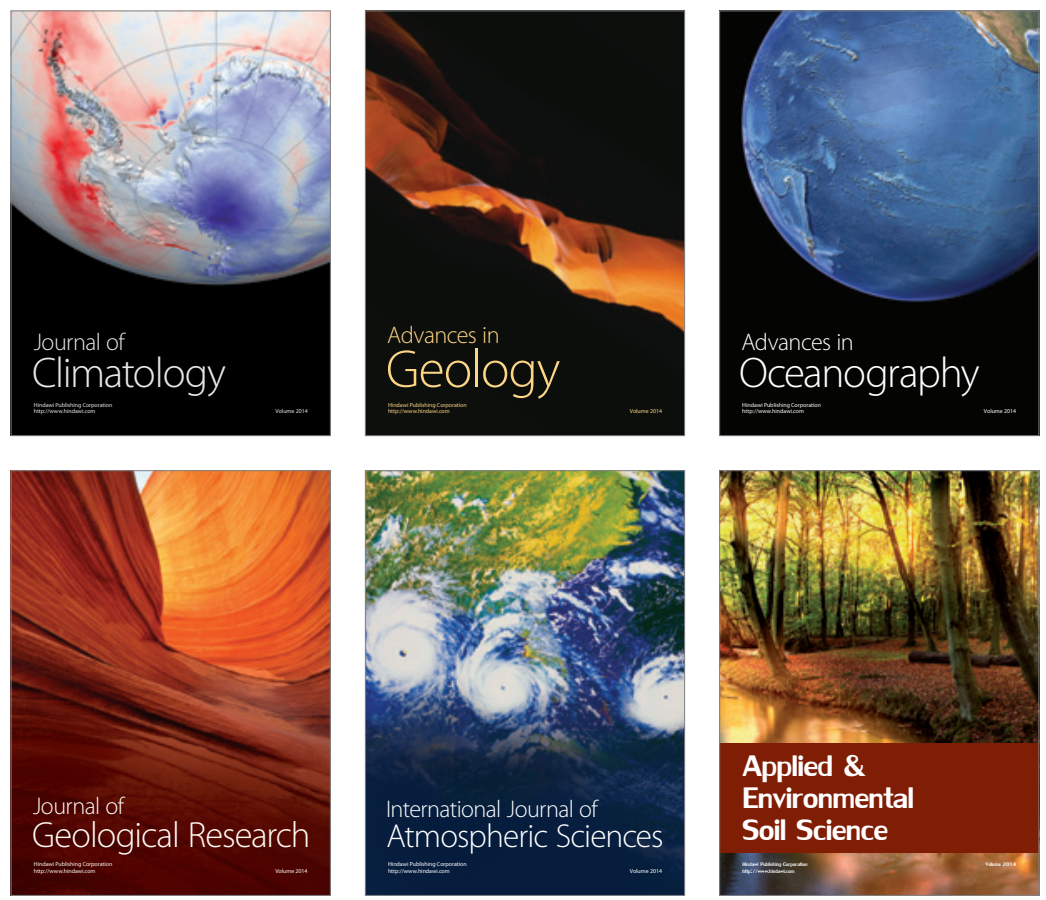
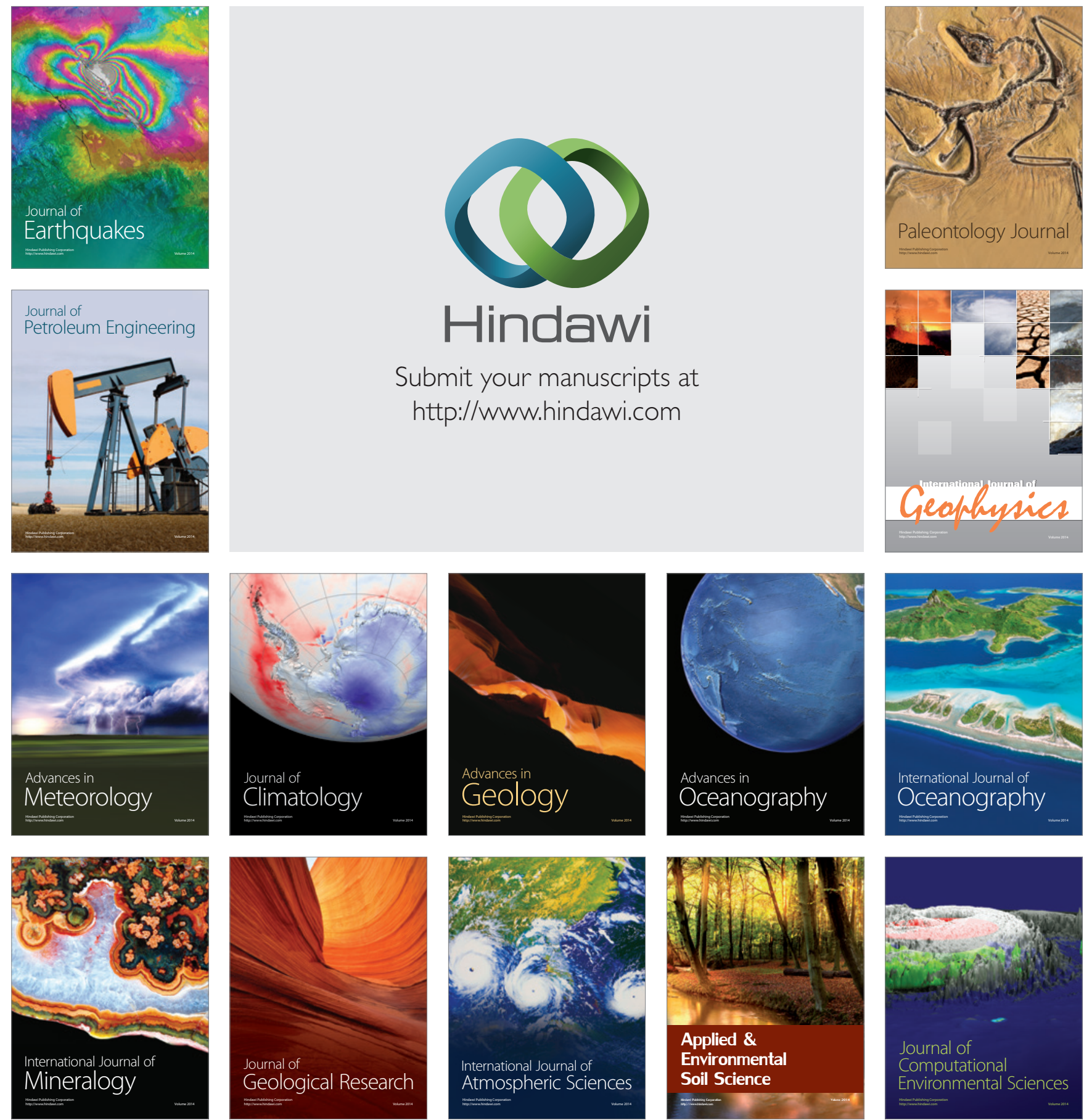